Ophthalmologica

\title{
Alagille Syndrome Associated with Myelinated Retinal Nerve Fibers
}

\author{
Bogomil Voykov ${ }^{\mathrm{a}}$ Emmanuella Guenova ${ }^{\mathrm{b}}$ Ekkehard Sturm ${ }^{\mathrm{c}}$ Christoph Deuter ${ }^{\mathrm{a}}$ \\ ${ }^{a}$ Centre for Ophthalmology and b Clinics for Dermatology, University Hospital Tübingen, and 'University Children's \\ Hospital Tübingen, Tübingen, Germany
}

\section{Key Words}

Alagille syndrome $\cdot$ Myelinated retinal nerve fibers - Optic disc anomaly $\cdot$ Posterior embryotoxon

\begin{abstract}
Purpose: Alagille syndrome is frequently associated with optic disc anomalies. This is the first report of a patient with Alagille syndrome and myelinated retinal nerve fibers. Methods: A 5-year-old female patient was referred to the Centre for Ophthalmology before a liver transplantation. Ocular examinations including slit lamp examination and funduscopy as well as anterior segment and fundus images were performed. Results: We observed myelinated retinal nerve fibers in both eyes of a 5-year-old female patient with Alagille syndrome. Conclusions: A broad spectrum of ocular anomalies is associated with Alagille syndrome. To our knowledge, this is the first reported case of myelinated retinal nerve fibers in a patient with Alagille syndrome.
\end{abstract}

Copyright $\odot 2009$ S. Karger AG, Basel

\section{Introduction}

Alagille syndrome is a rare autosomal-dominant disorder caused by mutations in the gene for the Notch signaling pathway ligand Jagged1 (JAG1), which are found in $94 \%$ of patients [1]. Other known mutations involve the gene for the Notch2 receptor (NOTCH2) [2]. The syn- drome is clinically defined by neonatal cholestatic jaundice with intrahepatic bile duct hypoplasia associated with additional findings, such as a characteristic face, ocular abnormalities, cardiovascular defects (frequently peripheral pulmonary artery hypoplasia or stenosis), and skeletal abnormalities. Mental and growth retardation and/or renal and endocrine abnormalities may also occur.

Ocular findings include posterior embryotoxon, iris abnormalities, optic disc anomalies, fundus changes (irregular pigmentation at the level of the retinal pigment epithelium, diffuse hypopigmentation, punchedout chorioretinal atrophy), and choroidal folds.

We report the first case to our knowledge of myelinated retinal nerve fibers in a patient with Alagille syndrome.

\section{Case Report}

A 5-year-old girl with Alagille syndrome was referred to the Centre for Ophthalmology before a liver transplantation.

The patient was born at term after a pregnancy complicated by papillomavirus infection in the 20th week of gestation. Both height and weight were small for gestational age. The parents were consanguineous, and 3 older siblings were healthy. After birth, clinical evaluation demonstrated bilateral stenosis of pulmonary

B.V. and E.G. contributed equally to this work.

\section{KARGER}

Fax +41613061234 E-Mail karger@karger.ch www.karger.com
(C) 2009 S. Karger AG, Basel

0030-3755/09/2235-0348\$26.00/0

Accessible online at:

www.karger.com/oph
Bogomil Voykov

Centre for Ophthalmology

Schleichstrasse 12-16

DE-72076 Tübingen (Germany)

Tel. +49 707129 83721, E-Mail bogomil.voykov@gmail.com 
arteries, pulmonary valve stenosis, atrial septal defect, and coarctation of the aorta. Liver biopsy at the age of 3 months showed bile duct hypoplasia, fibrotic extension of portal fields, and giant cell hepatitis. Persistent cholestasis developed and led to significant pruritus. Multiple cysts were found in the left kidney, and a mixed glomerular-tubular proteinuria developed. On chest X-ray, butterfly vertebrae were found. The child developed a characteristic facial appearance with a prominent forehead, hypertelorism, and deep-set eyes. On the basis of the clinical evaluation, a diagnosis of Alagille syndrome was established.

On ophthalmic examination, the visual acuity was 20/32 in both eyes. The actual visual acuity might be better, but the formal assessment was difficult because of somewhat reduced compliance. The patient was orthophoric and showed normal ocular movements. On slit lamp examination, a posterior embryotoxon was present in both eyes, and the anterior iris stroma appeared to be hypoplastic with prominent strands of tissue distributed in a radial pattern (fig. 1). There was no corectopia in either of the eyes. Pupil reactions were normal. The lens was clear in both eyes. The intraocular pressure could not be measured. Optic disc examination showed bilateral peripapillary myelinated retinal nerve fibers. The disc vasculature of the right eye was slightly anomalous. Both fundi showed a diffuse choroidal hypopigmentation with increased visibility of the choroidal blood vessels (fig. 2).

\section{Discussion}

Alagille syndrome has an estimated prevalence between $1 / 70,000$ and $1 / 100,000$ births $[3,4]$. It is a well-recognized multisystem disorder that includes paucity of intrahepatic biliary ducts, cholestatic facies, peripheral pulmonary artery hypoplasia or stenosis, butterfly-like vertebral arch defects, and variable ocular defects. These involve posterior embryotoxon (95\%), iris abnormalities (45\%), diffuse fundus hypopigmentation (57\%), speckling of retinal pigment epithelium (33\%), and optic disc anomalies (76\%) [5]. Obliquely oriented optic disc, temporal crescent, segmental swelling and pallor, optic nerve hypoplasia, tilted disc, optic disc drusen, anomalous vasculature, and optic pit were described in previous cases [5-7]. To our knowledge, there are no cases in the literature presenting an association of myelinated retinal nerve fibers with Alagille syndrome. Myelinated retinal nerve fibers have a reported prevalence of up to $1 \%$ of ophthalmic patients, and are bilateral in about $20 \%$ of affected individuals $[8,9]$. In most cases, it is a harmless finding with little, if any, influence on visual acuity and visual field. A rare condition associated with myelinated retinal

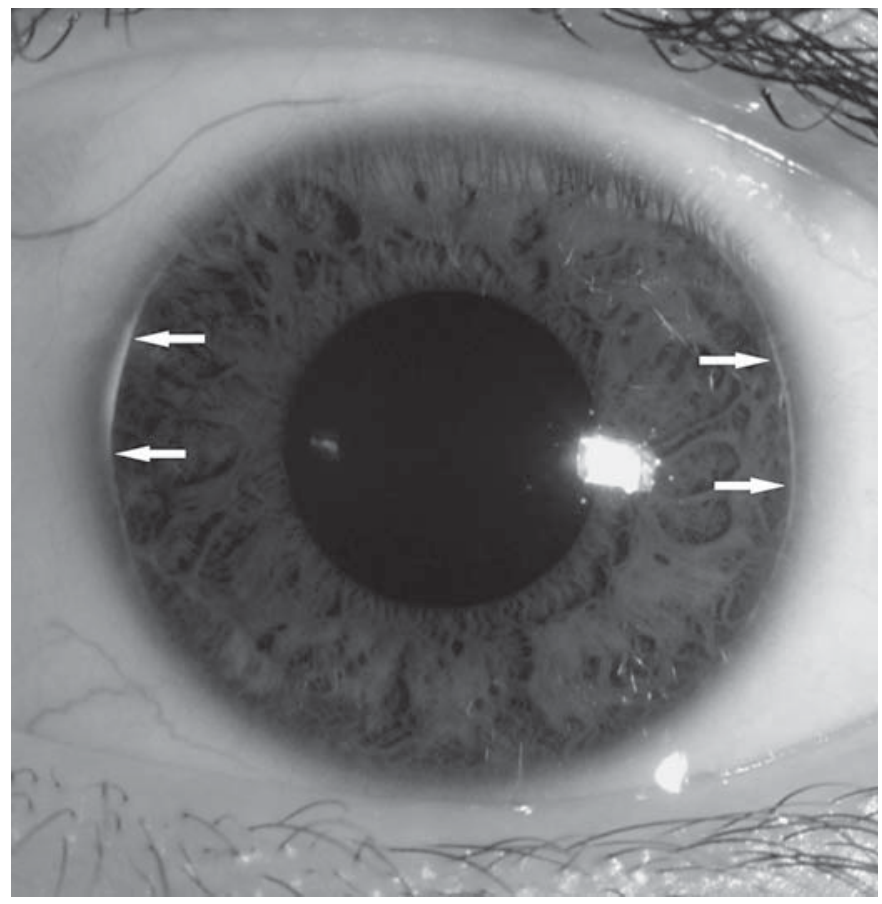

Fig. 1. Posterior embryotoxon (arrows), a common finding in patients with Alagille syndrome.
Fig. 2. Fundus photographs showing bilateral myelinated retinal nerve fibers. Additionally, a diffuse choroidal hypopigmentation with increased visibility of the choroidal blood vessels can be observed.

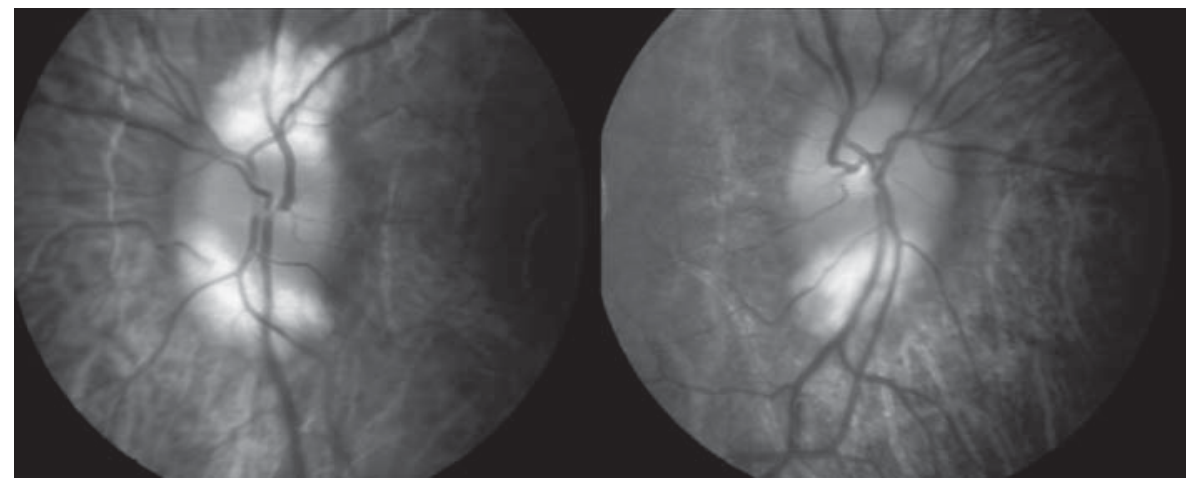


nerve fibers consists of ipsilateral extensive myelinated retinal nerve fibers, anisometropic myopia, amblyopia, and strabismus. Severer ocular and general abnormalities reported with myelinated retinal nerve fibers include coloboma, polycoria, keratoconus, oxycephalia, and other forms of dyscrasia $[8,10]$. None of these were present in our patient.
Since the prevalence of myelinated retinal nerve fibers and especially of Alagille syndrome is low, it might be expected that the number of patients having both anomalies would be low as well. Therefore, it is not clear whether this case represents a coincidental finding or an associated anomaly with Alagille syndrome. Further cases are necessary to answer this question.

\section{References}

1 Warthen DM, Moore EC, Kamath BM, et al: Jagged1 (JAG1) mutations in Alagille syndrome: increasing the mutation detection rate. Hum Mutat 2006;27:436-443.

-2 McDaniell R, Warthen DM, Sanchez-Lara $\mathrm{PA}$, et al: NOTCH2 mutations cause Alagille syndrome, a heterogeneous disorder of the notch signaling pathway. Am J Hum Genet 2006;79:169-173.

$>$ Elmslie FV, Vivian AJ, Gardiner H, Hall C, Mowat AP, Winter RM: Alagille syndrome: family studies. J Med Genet 1995;32:264268 .
4 Li L, Krantz ID, Deng Y, et al: Alagille syndrome is caused by mutations in human Jagged1, which encodes a ligand for Notch1. Nat Genet 1997;16:243-251.

$\checkmark 5$ Hingorani M, Nischal KK, Davies A, et al: Ocular abnormalities in Alagille syndrome. Ophthalmology 1999;106:330-337.

$\checkmark 6$ Kamoun R, Mili Boussen I, Beltaief O, Ouertani A: Drusen in children: three case studies (in French). J Fr Ophtalmol 2008;31:e1.

7 Fea A, Grosso A, Rabbione M, Grignolo F: Alagille syndrome and optic pit. Graefes Arch Clin Exp Ophthalmol 2007;245:315317.
Straatsma BR, Foos RY, Heckenlively JR, Taylor GN: Myelinated retinal nerve fibers. Am J Ophthalmol 1981;91:25-38.

$>9$ Kodama T, Hayasaka S, Setogawa T: Myelinated retinal nerve fibers: prevalence, location and effect on visual acuity. Ophthalmologica 1990;200:77-83.

10 Straatsma BR, Heckenlively JR, Foos RY, Shahinian JK: Myelinated retinal nerve fibers associated with ipsilateral myopia, amblyopia, and strabismus. Am J Ophthalmol 1979;88(part 1):506-510 